\title{
Assessment of Tourism Development In North Sulawesi Based On The Holistic Geotourism Perspective
}

\author{
Harley A.B. Mangindaan, Djabir Hamzah, Rahman Kadir, Indriyanti Sudirman \\ Faculty of Economic, Sam Ratulangi University, Manado, Indonesia \\ Faculty of Economic, Hasanuddin University, Makassar, Indonesia \\ Faculty of Economic, Hasanuddin University, Makassar, Indonesia \\ Faculty of Economic, Hasanuddin University, Makassar, Indonesia
}

\begin{abstract}
This study was conducted to examine the competitiveness of tourism in North Sulawesi based on a holistic perspective of geotourism. This study was specifically conducted in three regions of North Sulawesi, City of Manado, City of Bitung, and North Minahasa Regency. The method used in this research is descriptive qualitative with survey approach. Geotourism study was approached with the cutting-edge approach to what is called experience-oriented based that is gathering all stakeholders in order to determine destination competitiveness. The population in this study consisted of travelers/selected communities, tourism actors, and regulatory policy/government. The results showed that the existence of a gap between perspectives of respondents from group of supply side and demand side have to be solved by an alternative strategies for building of tourism Geotourism as holistic and competitive way. This study also shows that feature of geotourism only has small share in determining competitiveness. Factors of prospective management is the biggest factor in determining competitiveness, followed by a cost-competitive, complete, exotic, and integrated object.
\end{abstract}

Keywords: Geotourism, competitiveness, holistic approach

\section{Introduction}

North Sulawesi has a lot of potential resources with high attractiveness. However, not all of the attraction perform well. This issue is apparent from both the short length of stay of tourists, which average only about 1-4 days and the few number of visitations to North Sulawesi. The low tourist arrivals in North Sulawesi may mean that there are still many opportunities in this area that have not been exploited. If this opportunity can not be realized then the competitiveness of North Sulawesi will difficult to be reached.

Because tourism sector is a mutli-task that involved different sectors, firms and stakeholders in an economy, the partial approach is believed would affect negatively on the core sectors of tourism (attractions features) as well as the supporting sectors (infrastructure, accommodation, transport, tour and travel, authorities and organizations). To solve this problem it is necessary to apply a holistic approach in addressing to increase tourism destination competitiveness in North Sulawesi.

Diversity of attractions of North Sulawesi is very high. One that has not been explored is the geotourism features. Geotourism is one concept that specializes in tourism on geological and its formations. Geoturism is a good and important concept. As a good concept, geoturism is considered to involve the community, respect for local culture, and have a variety of types of attractions. As an important concept, geoturism is considered a very environmentally friendly, value added to the local community, good business, built on the idea of being "the sustainability of the concepts of past and future", and synergistic. Geotourism stakeholders may include investors, government planners, environmental groups and universities (Dowling, 2009).

Elements of geotourism include tourists visiting and learning to appreciate a destination. Geotourism add the main focus with the geological environment of plants (flora) and animals (fauna) (Hose, 20, 06; Newsome and Dowling, 2010; Robinson, 2010; Robinson and Percival, 2011; Serrano and Trueba, 2011), and a summary of the scenery, natural and cultural values, and landscape (Panizza 2001, Panizza and Piacente, 2003; Reynard, 2009). According Armenski et al (2011) and Fernando and Long (2012), natural resources of a destination determine the environment in the framework of a destination where visitors enjoy features including biotic, abiotic, and culture.

Destinations on the perspective of geotourism is to look for a protected heritage through resource conservation and environmental awareness (Robinson and Percival, 2011; Serrano and Trueba, 2011). Most researchers agree that the core resources that can attract visitors to a destination is a site based on environment and culture (Alhemoud and Armstrong, 1996; Faulkner et al., 1988).

Geotourism is understood as the uniqueness of the abiotic, biotic, and culture (ABC) feature that can be justified through the elements in a tourist attraction. Some of them are natural tourist attraction, artificial tourist attractions, cultural and social attractions. The strength of $\mathrm{ABC}$ feature will be equipped with elements of 
supporting infrastructure, regulation, promotion, and supporting communities that is attached in one tourism management. In this research concept, $\mathrm{ABC}$ features coupled with supporting features hereinafter referred to as the ABC PLUS feature. Eventhough destination approach of the attractions has been widely studied, understanding geotourism destination with attractions of the $\mathrm{ABC}$ plus is very rare.

Tourism phenomenon has two fundamental components, the origin and destination (Uysal, 1998) which later became the essence of the problem of tourism, namely the length of stay and the number of visits. Empirically measuring the success of the attraction destinations is tested through the evaluation of the two sides, the perspective of the supply and demand side. Supply perspective is based on the number and amount of the appeal of the destination provided. While the demand perspective depends on the perception and the interest of tourists in the area. Few studies were conducted to test the most important destination attraction contributes to this field since 1960 and 1970. Furthermore, after two decades that there are no studies that develop iterations of the ability of the model investigation of the attractions of the region through examination of the relationship between indicators of supply and demand. Nevertheless, there is little agreement on the terminology to define the core components of the supply side. Lew (1986), Pearce (1981), and Leiper (1979) refer to it as an attraction, while Ferrario (1976), Jafari (1982), and Smith (1987) uses the word resource. Gunn (1994) defines attraction as: "synergetic units of a tourism system". Gunn analyzes of various reference resources, but then agreed to use the word attraction as representative of natural resources and cultural. Due to the same use of the term "resource" and "attraction," in various studies, these two words are used in interchangeably and have the same meaning.

It is expected that with an understanding of the demand and supply side based on the perspective of geotourism, the tourism competitiveness of the North Sulawesi can be increased. During this time, various studies note that there is no literature that addresses the perspective of $\mathrm{ABC}$ plus features and analysis of supply and demand simultaneously to enhance the competitiveness of tourism. Therefore, this study was designed to analyse supply and demand side conditions of The North Sulawesi include ABC plus (natural and heritage resources, artificial resources, supporting factors, situational conditions, and destination management) to further used for formulating appropriate strategies to develop tourism in the North Sulawesi based on the holistic concept of geotourism.

\section{Research Methodology}

This research was conducted in three regions in North Sulawesi: Manado City, Bitung City, and North Minahasa Regency. The approach used in this study is a survey approach. The data collected from respondents expert (expert judgment) and other informants in response to items related to the constructs destinations, clusters, value chain for both the private, public (including academic), and the government.

The population in this study were all tourists visiting in North Sulawesi during the year of 2011 to 2012 and a panel of experts (expert panel) which consists of tourism authorities, tourism associations (hospitality, restaurant, tour and travel), academic, and independent tourism actors/NGOs. Further study is also descriptive for comparison with destinations of Raja Ampat, Wakatobi, Bali and Bunaken.

Variables were obtained through the following instruments: desk study, a panel of experts, focus group discussions, and observations. The variables obtained were then asked to the two groups of the population which is the supply group consisting of government officials, tourism actors, and NGOs, and the demand group consisting of tourists visit to this region and affected communities. Variables in both groups that were asked are Natural and Heritage Resources, Artificial Resources, Supporting Factors, Situational Conditions, and Destinations Management.

\section{Results And Discussion}

The observation of the condition of supply and demand concerning of geotourism plus in the three study sites can be seen in Table 1 .

Table 1 Conditions of supply and demand as well as a gap analysis of Main Variables in the Manado City, Bitung City, and North Minahasa Regency

\begin{tabular}{|c|c|c|c|c|c|c|c|c|c|c|c|c|}
\hline \multirow{2}{*}{ Destination Variable } & \multicolumn{4}{|c|}{ Manado } & \multicolumn{4}{|c|}{ Bitung } & \multicolumn{4}{|c|}{ North Minahasa } \\
\hline & DS & SS & GAP & $\% \mathrm{Kss}$ & DS & SS & GAP & $\% \mathrm{Kss}$ & DS & SS & GAP & $\% \mathrm{Kss}$ \\
\hline Inheritted Resources & 4,77 & 3,98 & 0,79 & 83,4 & 4,62 & 3,98 & 0,64 & 86,1 & 4,76 & 3,60 & 1,16 & 75,7 \\
\hline Artificial Resources & 4,66 & 4,05 & 0,61 & 86,9 & 4,55 & 2,27 & 2,28 & 49,9 & 4,52 & 2,51 & 2,01 & 55,6 \\
\hline ABC Variables & 4,72 & 4,01 & 0,70 & 85,2 & 4,59 & 3,13 & 1,46 & 68,05 & 4,64 & 3,06 & 1,58 & 65,6 \\
\hline Supporting Factor & 4,76 & 3,79 & 0,97 & 79,6 & 4,72 & 3,18 & 1,55 & 67,3 & 4,67 & 2,90 & 1,77 & 62,2 \\
\hline Situational Condition & 3,61 & 3,38 & 0,23 & 93,6 & 3,57 & 2,21 & 1,36 & 61,9 & 3,10 & 1,88 & 1,21 & 60,8 \\
\hline Destination Management & 4,64 & 3,47 & 1,18 & 74,7 & 4,51 & 2,76 & 1,75 & 61,2 & 4,61 & 2,67 & 1,95 & 57,8 \\
\hline Plus Variables & 4,32 & 3,54 & 0,78 & 83,1 & 4,27 & 2,72 & 1,55 & 63,45 & 4,13 & 2,49 & 1,64 & 60,3 \\
\hline Averages & 4,50 & 3,78 & 0,74 & 83,6 & 4,43 & 2,92 & 1,51 & 66 & 4,38 & 2,77 & 1,61 & 63,2 \\
\hline
\end{tabular}


Notes:

SS: Supply Side

DS: Demand Side

Kss: Similarity

Lower value of supply relative to that of demand showed in the Table 1 can be said as factors that reduce the destination competitiveness of North Sulawesi. The absence of good services/facilities (infrastructure) although the presence of tourism resources feature will not help increase the competitiveness of the destination. As a consequence, it can be said that all core resources of tourism provided are not good enough to attract tourists to visit this area. It is true as showed by North Minahasa Regency that provides a variety of attractions but not able to increase visitation.

Supply side is a good predictor of economic measures and demand side does not seem in accordance with the facts on the tourism site. It can be seen that in the case of the city of Manado, it tends to prioritize more abiotic features (specifically Bunaken National Marine Park) but less in other features. As a consequences, many tourists do not satisfy in the course of visiting in this city. From the case of Manado, it is seen that there are many interesting features in addition to the features of ABC that can be maximized to attract tourists. Similar conditions are also indicated by the other two regions. This data is reinforced by the analysis that puts various supporting factors that are considered more important than that of features of tourism objects. According to Fernando and Long (2012), modern tourism is "experience" oriented, based on competitiveness rather than comparative scenic beauty in a destination. Therefore, ABC features provided by North Sulawesi must be understand only as foundation for competitiveness.

Significant differences between the conditions of supply and demand suggests that the conditions of geotourism in North Sulawesi has not been in line with expectations. Average of results of data analysis shows that the smallest gap (which arise due to differences in the value of the supply and demand) is shown by the city of Manado, followed by Bitung and the district of North Minahasa.

In the city of Manado, the largest gap is indicated by the supporting factors and destination management. While the smallest gap is shown by the situational condition. In general, it appears that gap of supporting variable (PLUS) is greater than the variable of $\mathrm{ABC}$ feature.

Conditions similar to Manado is also shown by Bitung that demonstrated that the gap of PLUS variables larger than the gap of $\mathrm{ABC}$ variables. Management destination together with artificial resources shows a relatively larger gap than that of the other major variables. While the smallest gap indicated by the inheritted resources.

For North Minahasa regency, the smallest gap is indicated by the inheritted resources and the biggest gap is indicated by the artificial resources. While in general, the gap of ABC variables is slightly larger than that of PLUS variables.

The comparison results indicate that the variable of tourism destinations in the city of Manado has an advantage in all variables when compared with the other two regions, but for all destinations observed, the value of the feature core resources (ABC) has a lower value than that of supporting factors (Plus).

The data shows that all main variables showed a gap between the core tourist attraction with expectations of tourists. These results generally show that the availability of the ABC on the supply side does not guarantee the interest of tourists for visiting the intended destination. Many tourists are disappointed with the offer destinations which in reality do not match as promoted.

Some references indicate that the size of the destination's competitiveness is not enough just to look at and analyze the availability of supply because the assumptions and perceptions about tourist destinations may not always translate into actual visits. Therefore, it is very important for further analyze the perception of visitors to the features provided by a tourist destination area. The features that are considered to be good by the providers is not necessarily perceived well by the service recipient so often there is a gap. The smaller the gap, the more successful of destinations that provide and manage tourist facilities. On the other hand it can be seen through a gap analysis on what features that the service recipient are not satisfied, and vice versa. Also on what features which destination give excess services while tourists do not consider it as important service.

This study provides an understanding that the destination market and tourism planners need to consider how the destination competitiveness can be measured and how the implications arising from supply and demand. Tourism planners typically design tour packages based on market supply and develop appropriate destination based on the current promotional strategies for incoming travelers. Both of these approaches is likely to be counterproductive if used separately.

Determination of the relationship between supply and demand also has implications for resource allocation. If the area has comparative scenic beauty but not well perceived by tourists, than it is necessary to develop, enhance, and accelerate its portfolio. The fact that usually resource allocation is based on criteria that 
less attention to the interaction of supply and demand side. The result will be ineffective because the existing resources merely to survive not to function properly.

The results showed that the performance of each destination in North Sulawesi region which is reflected through the gap between what is provided by the destinations to what the expectations of tourists, shows that in general the city of Manado is consider the best destination with the best service with a suitability value of expectation and reality that reached $83.6 \%$ compared to the other two areas, the city of Bitung $(66 \%)$ and North Minahasa district (63.2\%). Performance of PLUS variables, from ABC features, which include; supporting variables, situational conditions and destination management of the all destination studied is still lower than the performance of $\mathrm{ABC}$ features.

Further analysis shows that the supporting variables that needs serious attention because it provides very low satisfaction scores compared to other supporting variables is variables of situational conditions and destination mangement. This happens in all three areas or regions. Situational conditions variables include safety, as well as the development of business relationships and the development of sustainable tourism. The presence of regulation of environmental protection, business relations with the origin of tourists, and security of foreign tourists are three variables forming the critical value to be a major concern, in addition to other variables such as commitment and community participation in sustainable tourism development. Destination management include mainly service quality, hospitality, and competitive cost. This phenomenon occurs in all three areas of North Sulawesi, but the main variable than all the critical variables is that there is a problem of safety and criminal for all destination.

The results of this study also provide the design of integrated strategic implications. In this case, biotic features offered more than what is obtained in accordance with the demand perspective. Yet according to the observations seen that prospective managerial provide the greatest share of competitiveness compared to availability of the $\mathrm{ABC}$ (Figure 1). In other words, the most appropriate strategy implemented is strengthening the management and tourist authorities who should have a vision that far ahead. Competitive costs is the next important factors followed by complete, exotic, and integrated objects provide by destination, and then the less important is the core resources of tourism that is natural, cultural, and artificial resources. In other words, the availability of natural and artificial features (feature $\mathrm{ABC}$ ) has no meaning at all in the absence of a prospective management, cost competitive, and a complete, exotic, and integrated attraction.
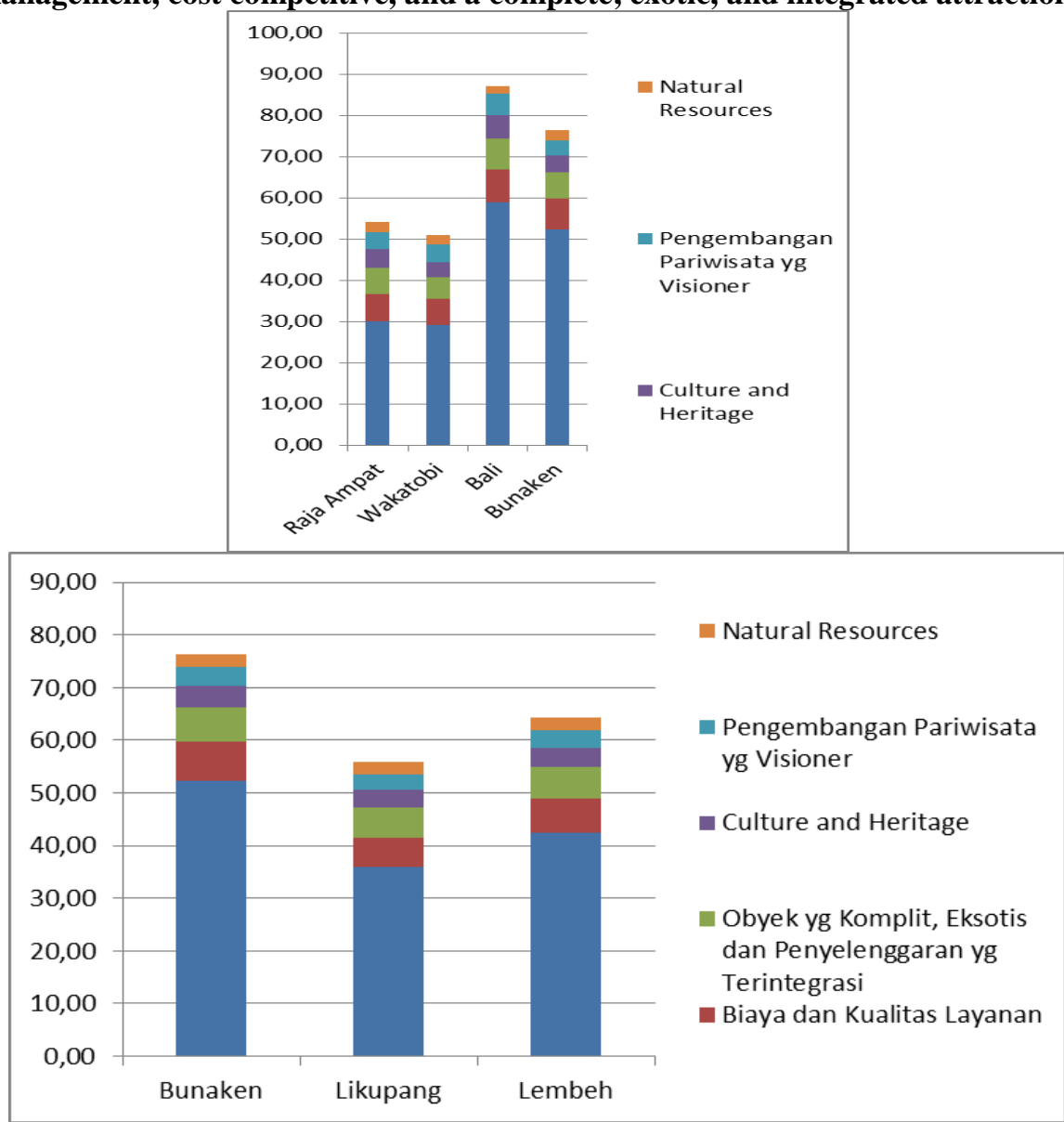

Figure 1. Sharing Variables Determinants of Competitiveness 
The conceptual model offered by this study leads to an integrated approach to measure the tourism competitiveness of North Sulawesi. This approach raised a comparative advantage in all three study areas (feature $\mathrm{ABC}$ ) to be competitive with more attention on supporting the tourism sector (restaurants, hotels, events/activities, attractions, transport, etc.), quality management, worker skills, and government policies.

More detail can be seen in the example of cluster formation on one of the leading tourist in North Sulawesi, namely Bunaken Marine Park. It is known that the core resources of the Park is the natural resources (marine parks, historic sites and local culture) and artificial resources (game outdoors, recreation, sports activities, etc.).

Factors supporting (suppliers and visitors) together with a core resources (features $\mathrm{ABC}$ ) will provide a basic foundation for a sustainable tourism industry and improving the competitiveness of North Sulawesi. The presence of core resources, in this case the Bunaken Marine Park, will not be enough to generate sustainable tourist visits if the absence of tourism infrastructure such as accommodation, transport, event/special events organized, entertainment/ entertainment and shopping. All of this, thus, facilitating tourist visits in this area. In other terms, the attributes mentioned above represent the so-called "value added" in terms of overall tourism product. Broadly speaking, the core resources and contributing factors have the causality relations and construct the competitive advantage of Bunaken destination.

Destination management variables played by government and tourism business communities can enhance the appeal to core resources, and strengthen the effectiveness and quality of support resources. A similar opinion was also mentioned by Crouch and Ritchie (1999). Cluster model on Bunaken combines two management sector runned by both the private sector and the government sector. Both of these sectors can combine the activities undertaken by the tourism industry associations/hospitality, raising funds for the purpose of joint marketing programs, training programs, implementation of environment-based tourism operations, and develop an integrated regional tourism strategy regarding marketing and promotion, workforce development, and environmental and cultural protection.

Destination/cluster competitiveness of North Sulawesi, as such, is the overall result of the model clusters associated with all variables (heritage resources, artificial resources, supporting factors, situational conditions, and management of destination). Determinant variables in the study lies in the PLUS variables. In addition to being a determinant of the competitiveness of the North Sulawesi tourism, this variable should also get more attention because the observations indicate that there is a large gap of this determinant variables. This means that our focus on core resources do not provide any impact on the competitiveness of tourism. Strategies to close the gap on variables to improve the competitiveness of PLUS variables is one of the holistic approach to improve the competitiveness of tourism in North Sulawesi.

Each region must be developed to synergize together to develop tourism in North Sulawesi. Competition among the three regions should be avoided. Each area should be developed based on their areas of competence. Each destination region should raise the potential attraction they have and avoid competition with other regions in the cluster. The tendency to develop the same potential in each region is possible, especially for tourist features which are available naturally in nature, but both the features must be differenciate or be specialized so that they can connect with each other and do not give rise to competition. It must be produced a clear mapping for each region to develop the potential attraction of each regions. Development of tourism infrastructure will be tailored to the needs of each region based on the mapping has been done, except for public infrastructure. Each region should be developed jointly, synergrtically, without make discrimination that would reduce the competitiveness of the cluster, which will eventually turn to the overall competitiveness.

Tourism outhority at the provincial level have a role to manage the cluster as a whole in the development of tourism in North Sulawesi, each advantage of each region must be developed as a package of mutual support in order to increase the competitiveness of the region. Old concept of tourism development has been proven that it is not efficiently and effectively succeeded in developing the tourism competitiveness. Holistic concept of tourism development in the developing North Sulawesi tourism cluster that synergizes three regions of Ma nado, North Minahasa and Bitung with all the potential advantages and disadvantages in each regions, and is supported by a prospective tourism management will be a concept of tourism development that can improve North Sulawesi tourism competitiveness. Increasing of North Sulawesi tourism competitiveness would be level North Sulawesi position with a national tourism destination that can synergize together with other provinces in improving the competitiveness of the national tourism, which in turn, can demonstrate country contribution to the development of international tourism.

Manado city that excels in infrastructure, situational conditions, and destination management can be supported by core resources that can be supplied by the City of Bitung and North Minahasa Regency. Collaboration instead of competition is the key to success in improving the competitiveness of tourism in North Sulawesi. 
Through this strategy and based on reasoning to provide services to tourists in a more focused, collective and efficient, it will develop the limited resources in North Sulawesi to reach wider tourist perceptions and finally win tourists visitation.

\section{Reference}

[1] Dowling RK. 2009. Geotourism's contribution to local and regional development. In: de Carvalho C, Rodrigues J (eds) Geotourism and local development. Camar municipal de Idanha-a-Nova, Portugal, pp 15-37

[2] Hose, Thomas A. 2006. Geotourism and interpretation In Dowling R.K.\& Newsome D.(Eds): Geotourism-221-241,OxfordBurlington (Elsevier Butterworth-Heinemann).

[3] Newsome, D., and Dowling, R.K. 2010. The Tourism of Geology and Landscape. Goodfellow Publishers Limited. (diakses 23 November 2012).

[4] Robinson, A.M. 2010. Australian Geotourism - Current Challenges and Future Opportunities. The Linnean Society of NSW Symposium. (diakses 23 November 2012).

[5] Robinson, A.M., and Percival, I.G. 2011. Geotourism, Geodiversity and Geoheritage in Australia-Current Challenges and Future Opportunities. Foreword to Papers from a Symposium on Geodiversity, Geological Heritage and Geotourism. Proceedings of the Linnean Society of New South Wales 132, 1-4.

[6] Serrano, E., and Trueba, J.J.G. 2011. Environmental Education and Landscape Leisure. Geotourist Map and Geomorphosites in The Picos De Europa National Park. GeoJournal of Tourism Geosites. 8 (2): 295-308.

[7] Panizza M. \& Piacente S. 2003. Geomorfologia Culturale. Pitagora Editrice, Bologna, 350 pp.

[8] Panizza M. 2001. Geomorphosites: Concepts, methods and examples of geomorphological survey. Chinese Science Bulletin, 46, 46.

[9] Reynard E. 2004. Géotopes, géo(morpho)sites et paysages géomorphologiques. In: E. Reynard \& J.-P. Pralong (Eds.), (Paysages géomorphologiques). Travaux et Recherches, 27, Lausanne, 124-134

[10] Armenski, T., Gomezelj, D. O., Djurdjev, B., Deri, L., \& Aleksandra, D. 2011. Destination Competitiveness: A challenging Process for Serbia. Journal of studies and Research in Human Geography, 5.1, 19-33.

[11] Fernando I N and W. Long. 2012. New Conceptual Model on Cluster Competitiveness: A New Paradigm for Tourism?. International Journal of Business and Management. Vol. 7, No. 9; May 2012.

[12] Alhemoud, A.M. and Armstrong, E.G. 1996. Image of Tourism Attractions in Kuwait. Journal of Travel Research, (Spring), 76-80.

[13] Faulkner, B., Oppermann, M., and Fredline, E. 1999. Destination Competitiveness: An exploratory examination of South Australia's core attractiveness. Journal of Vacation Marketing, 5(2): 125-139.

[14] Uysal, M. 1998. The Determinants of Tourism Demand: A Theoretical Perspective. In Ioannides, D. and Debbage, K.G. (eds.), The Economic Geography of the Tourist Industry, 79-98.

[15] Lew A. 1986. Guidebook Singapore: The spatial organization of urban tourist attractions. Unpublished Ph.D. Dissertation, Department of Geography, University of Oregon.

[16] Pearce, D.G. 1981. Tourist Development. New York: Longman.

[17] Leiper, N. 1979. The model of tourism. Towards a definition of tourism, tourist, and the tourist industry. Annuals of Tourism Research, 6(4): 390-407.

[18] Ferrario F. 1976. The tourist landscape: A method of evaluating tourist potential and its application to South Africa. Unpublished Ph.D. Dissertation. Geography, University of California, Berkley.

[19] Jafari, J. 1982. The Tourism Market Basket of Goods and Services: The Components and Nature of Tourism. In Studies in Tourism Wildlife Parks Conservation

[20] Smith, L.J.S. 1987. Regional Analysis of Tourism Resources. Annuals of Tourism Research. 14 (2): $254-273$.

[21] Gunn, C.A. 1994. Tourism Planning (third edition), London: Taylor \& Francis.

[22] Crouch, G.I., \& Ritchie, J.R. 1999. Tourism, Competitiveness and Societal Prosperity. Journal of Business Research, 44(3), 137152. 